This is the peer reviewed version of the following article: Homer Caroline et al. 2011, 'Planned vaginal delivery or planned caesarean delivery in women with extreme obesity', Blackwell Publishing Ltd, vol. 118, no. 4, pp. 480-487. which has been published in final form at http://dx.doi.org/10.1111/j.1471-0528.2010.02832.x This article may be used for non-commercial purposes in accordance With Wiley Terms and Conditions for self-archiving' 
Homer CSE, Kurinczuk J, Spark P, Brocklehurst P, Knight M. (2011) Planned vaginal delivery or planned caesarean delivery in women with extreme obesity. BJOG: British Journal of Obstetrics and Gynaecology 118 (4): 480-487.

\section{PLANNED VAGINAL DELIVERY OR PLANNED CAESAREAN DELIVERY IN WOMEN WITH EXTREME}

OBESITY

Homer $\mathrm{CSE}^{1,2}$, Kurinczuk JJ ${ }^{1}$, Spark $\mathrm{P}^{1}$, Brocklehurst $\mathrm{P}^{1}$, Knight $\mathrm{M}^{1}$

${ }^{1}$ National Perinatal Epidemiology Unit, University of Oxford, UK

${ }^{2}$ Centre for Midwifery, Child \& Family Health

Faculty of Nursing, Midwifery and Health

University of Technology Sydney, Australia

Correspondence to:

Marian Knight

National Perinatal Epidemiology Unit

University of Oxford

Old Rd Campus

Oxford

OX3 7LF

Tel: 01865 289727, Fax: 01865289701

Marian.knight@npeu.ox.ac.uk

Word Count: 1,981

Abstract: 185

Tables: 4

Figures: 1

Running title: Mode of birth in extreme obesity

Keywords: Obesity, pregnancy, caesarean delivery, mode of birth 


\section{Abstract}

Objective: To compare the outcomes of planned vaginal versus planned caesarean delivery in a cohort of extremely obese women (BMI_ $50 \mathrm{~kg} / \mathrm{m}^{2}$ or greater).

Design: A national cohort study using the UK Obstetric Surveillance System (UKOSS).

Setting: All hospitals with consultant-led maternity units in the UK.

Participants: 591 extremely obese women delivering in the UK between September 2007 and August 2008.

Methods: Prospective cohort identification through UKOSS routine monthly mailings.

Main Outcome Measures: Anaesthetic, postnatal and neonatal complication rates.

Results: After adjustment, there were no significant differences in anaesthetic, postnatal or neonatal complications between women with planned vaginal delivery and planned caesarean delivery, with the exception of shoulder dystocia ( $3 \%$ vs $0 \%, p=0.019$ ). There were no significant differences in any outcomes in the subgroup of women who had no identified medical or antenatal complications.

Conclusions: This study does not provide evidence to support a routine policy of caesarean delivery for extremely obese women on the basis of concern about higher rates of delivery complications, but would support a policy of individualised decision on mode of delivery based on a thorough assessment of potential risk factors for poor delivery outcomes. 


\section{Introduction}

Obesity is a growing global public health problem and a major contributor to the global burden of chronic disease and disability (1). Obesity has significant implications for the provision of maternity care both in relation to increased risks and complications for both mother and baby, and its association with an increased risk of caesarean delivery. A recent systematic review of 11 cohort studies reported that the risk of caesarean delivery was increased by $50 \%$ in women with a body mass index (BMI) of 30-35 $\mathrm{kg} / \mathrm{m}^{2}$ and more than double in women with a BMI>35 kg/m ${ }^{2}$ compared with women with a normal BMI $\left(20-25 \mathrm{~kg} / \mathrm{m}^{2}\right)(2)$. Factors associated with the higher risk of caesarean delivery in obese women may include medical and pregnancy complications such as diabetes and pre-eclampsia, as well as poor uterine contractility (3) and concerns regarding the challenges of both general and regional anaesthesia in the emergency situation $(4,5)$. Anecdotally, there appears to be an increasing move to recommend planned caesarean delivery to avoid the perceived risks of emergency caesarean delivery in this group of women. However, earlier studies have highlighted increased morbidity and mortality associated with caesarean delivery in obese women, (6) longer operative times and length of hospital stay with blood loss and postoperative infective morbidity being greater $(7,8)$. Recent consensus standards on the management of women with obesity in pregnancy make no recommendation concerning caesarean delivery due to lack of evidence to inform advice (9). There is thus an urgent need for evidence to inform the development of clinical policy on the planned mode of delivery in this group of high risk women.

The aim of this study was to investigate, using data from a UK national cohort of pregnant women with a $\mathrm{BMI} 50 \mathrm{~kg} / \mathrm{m}^{2}$ or over (10), the factors associated with mode of birth, and to compare the outcomes in women planned to deliver vaginally with those planned to deliver by caesarean. 


\section{Methods}

The cohort of extremely obese women was identified through the UK Obstetric Surveillance System (UKOSS) (11) between September 2007 and August 2008 and the methods of identification have been fully described elsewhere (10). The study included pregnant women who, at any point in pregnancy, had a body mass index (BMI) of $50 \mathrm{~kg} / \mathrm{m}^{2}$ or greater and had data for mode of birth and urgency of caesarean delivery (Figure 1).Women were divided into two groups based on the planned mode of delivery. Women who laboured or who had an induction of labour were included in the planned vaginal group and women who were delivered by caesarean without labour were included in the planned caesarean group. Characteristics were compared between the two groups using the Chi squared and Fishers exact tests.

A multivariable logistic regression model was used to examine predictive factors for caesarean delivery. We developed a pragmatic model by including factors known from the literature to be associated with caesarean delivery particularly in obese women. The factors included were age, ethnicity, socioeconomic status based on occupation, previous caesarean delivery, diagnosed diabetes including current gestational diabetes, multiple pregnancy and BMI. Continuous variables were tested for departure from linearity by the inclusion of quadratic terms in the model and subsequent likelihood ratio testing on removal. Potential interactions between each variable and every other variable in the model were tested by the addition of interaction terms and subsequent likelihood ratio testing on removal. $\mathrm{P}<0.05$ was considered evidence for significant interaction or departure from linearity. Unadjusted and adjusted odds ratios (OR) and 95\% Cls were calculated.

Outcomes were compared between the two groups in a further multivariable model, adjusting for potential confounders identified from the literature (pre-existing: diabetes, asthma, hypertension or endocrine disorder; and/or current: gestational diabetes, pre-eclampsia or a thromboembolic event in 
this pregnancy, previous delivery by caesarean section). Neonatal outcomes were additionally adjusted for preterm delivery. A sensitivity analysis was conducted to explore the outcomes in the group of women who had no reported antenatal or medical complications (pre-existing: diabetes, asthma, hypertension or endocrine disorder; and/or current: gestational diabetes, pre-eclampsia or a thromboembolic event in this pregnancy ) by repeating the comparison of outcomes excluding women with any of these known complications.

All analyses were carried out using STATA 10 software (StataCorp, College Station, TX).

\section{Results}

This analysis included 591 women who met the study inclusion criteria (Figure 1). The median BMI was 55 with a range from 50.0 to 80 . Of the 591 women, 174 (29.4\%) were in the planned caesarean group and 417 (70.6\%) were in the planned vaginal group. Of those who planned a vaginal delivery, 30.5\% ( $n=127$ ) went on to have a caesarean delivery. Characteristics of women according to planned mode of delivery are shown in Table 1. Women in the planned caesarean group were significantly older, of higher parity and more likely to have essential hypertension, previous hypertensive disorders of pregnancy, previous caesarean delivery, a multiple pregnancy or current gestational diabetes. In a logistic regression model, after controlling for age, ethnicity, socio-economic status and the other variables in Table 1, the factors associated with a significantly higher odds of actual caesarean delivery were a previous caesarean delivery and pre-existing diabetes or gestational diabetes and (Table 2). Of the 26 women in the planned vaginal delivery group who had a previous caesarean delivery, only 9 (35\%) delivered vaginally. There was a three-fold increase in the risk of caesarean delivery associated with multiple pregnancy; this was not statistically significant but it should be noted that due to small numbers this comparison has limited power to demonstrate statistical significance. 
Admission to a neonatal intensive care unit was more likely in the infants born to women undergoing a planned caesarean delivery on univariate analysis. However, after adjustment, there were no significant differences in anaesthetic, postnatal or neonatal complications between women with planned vaginal delivery and planned caesarean delivery (Table 3), with the exception of shoulder dystocia. None of the 13 infants born following shoulder dystocia were reported to have suffered permanent injury. The sensitivity analysis showed that there were no significant differences in any outcomes in the subgroup of women who had no identified medical or antenatal complications (Table 4), although it should be noted that there was a $66 \%$ lower risk of major maternal morbidity in the planned vaginal group (not statistically significant).

\section{Discussion}

This study did not identify any statistically significant differences in anaesthetic, maternal postnatal or neonatal complications according to planned mode of delivery in a national cohort of extremely obese women in the UK after adjusting for maternal medical and antenatal complications, other than in the occurrence of shoulder dystocia. None of the infants suffered permanent injury. All the other complications examined, with the exception of postnatal wound complications, occurred less frequently in the planned vaginal group than the planned caesarean group, although again the differences were not statistically significant, possibly due to limited study power even in this national cohort study. When we examined the subgroup of women with no identified medical or antenatal complications, we were unable to identify any differences in any of the complications examined.

Other studies addressing this issue are few and have focused particularly on planned mode of delivery in obese women who have undergone a previous caesarean delivery, reporting poorer outcomes amongst those undergoing a trial of labour compared with elective repeat caesarean delivery $(12,13)$. In contrast, we studied the entire group of extremely obese women and not a selected group, and after adjusting for 
potential confounders did not demonstrate any differences in outcomes with the exception of shoulder dystocia without permanent injury. In our analysis of women without any documented medical or antenatal complications there were no significant differences, although it should be noted that even large national studies such as this have limited power to detect differences in rare outcomes. This study does not provide any evidence to support a policy of routine caesarean delivery for extremely obese women on the basis of concern of higher rates of delivery complications, but would support a policy of individualised decision on mode of delivery based on a thorough assessment of potential risk factors for poor delivery outcomes. Such a policy would be supported through guidance such as that available to inform the care of women undergoing birth after previous caesarean birth (14).

The definition and accuracy of reporting of shoulder dystocia is an important factor in interpreting the incidence of shoulder dystocia. In practice, some clinicians only report a birth as involving shoulder dystocia if they had to employ specific manoeuvres to deliver the baby's anterior shoulder. Others will record shoulder dystocia if there is any delay in the emergence of the shoulder following delivery of the head. It is possible in this cohort that the existence of the women's extreme obesity ensured a high index of concern in the minds of the clinicians for shoulder dystocia and any difficulties delivering the baby was defined as shoulder dystocia. Nevertheless, $2.2 \%$ of babies were born following shoulder dystocia. This is higher than many other reported rates although studies report a wide variation in incidence. Unselected population studies in North America and the UK found a 0.6\% incidence (15-17). Shoulder dystocia is known to increase with fetal macrosomia. For example, an incidence of $14.3 \%$ has been reported in babies with a birthweight of $4500-4750 \mathrm{~g}$, and $21.1 \%$ for those $4750-5000 \mathrm{~g}$ in a population based study in California (18). In this cohort, nearly $10 \%$ of babies weighed $4500 \mathrm{~g}$ or more at birth; over $60 \%$ of these were in the planned vaginal delivery group suggesting that more accurate assessment of fetal weight may be beneficial. Unfortunately, estimating fetal weight is particularly 
challenging in women with a high BMI as conventional methods, such as ultrasound scanning in late pregnancy, are likely to be difficult, inaccurate and in some cases, not possible at all. Abdominal palpation and fundal height measurement are also not likely to be helpful in predicting the size of the baby. Other measures such an MRI scanning are also limited by the size of the machine and the cost and availability.

One of the main concerns about caesarean delivery for women with extreme obesity has been the risk of anaesthetic complications in the emergency situation. A recent study of difficult and failed intubation in obstetric anaesthesia found that women whose tracheas proved difficult to intubate had a weight range of 50 to $140 \mathrm{~kg}$ (median $80 \mathrm{~kg}$ ) while those in whom intubation was straightforward ranged from 50 to $73 \mathrm{~kg}$ (median $57 \mathrm{~kg}$ ) (19). In their logistic regression analysis however, a weight of $100 \mathrm{~kg}$ or more was not an independent predictor of a difficult intubation. This may have been due to the small sample size in the difficult intubation group (36 of 1095 patients) and the sole use of weight, rather than BMI. A study of failed intubation for obstetric anaesthesia is currently being conducted to investigate the role of $\mathrm{BMI}$ in failed intubation further (20). Anaesthetic complications were rare in our cohort, and there were no differences between the planned vaginal and planned caesarean groups.

Randomised controlled trials in the context of uncommon pregnancy conditions such as extreme obesity are challenging and national cohort studies such as this provide high quality evidence in the absence of randomised controlled trials, as they are free from most of the biases of centre-based observational studies. Nevertheless, the study design does have limitations. We identified clear differences between the groups planned to deliver vaginally and those planned to have a caesarean delivery reflecting the clinical decision-making which underlies the choice of mode of delivery and we therefore adjusted for these in our analysis. It is likely, however, that there are other differences between the two groups which we have not identified and therefore have not been able to adjust for. UKOSS was also the only 
source of data used in the absence of any other available source; however, previous studies using this system have suggested a high rate of case ascertainment (21-23). The study was conducted in a well developed health system and as such, the results cannot be generalised to less developed health systems. It is likely that the health care for this group of women in countries such as the USA, Australia and much of Europe will be similar and therefore the results are likely to be generalisable to these settings. 


\section{ACKNOWLEDGEMENTS}

The authors thank the United Kingdom Obstetric Surveillance System (UKOSS) reporting clinicians who notified cases and completed the data collection forms. The authors also acknowledge the assistance of the UKOSS Steering Committee and the support of the Royal College of Obstetricians and Gynaecologists, Royal College of Midwives, Obstetric Anaesthetists Association, Faculty of Public Health, National Childbirth Trust, and the Confidential Enquiry into Maternal and Child Health.

\section{DISCLOSURE OF INTERESTS}

We do not have any interests to declare in relation to this study.

\section{CONTRIBUTION TO AUTHORSHIP}

$\mathrm{CH}$ undertook this particular analysis and wrote the first draft of the paper. JJK assisted with the design of the study and supervised the data collection and analysis and contributed to writing the paper, PB had the original idea for the surveillance system, provided advice at every stage of the study and contributed to the writing and editing of the paper. PS assisted with data coding, conducted validation of the data and contributed to writing the paper. MK is the lead investigator on UKOSS and is responsible for the overall design and conduct of the study as well as leading this analysis and working on subsequent drafts of the paper. All authors provided comment and approved the final version of the paper and the submission. MK will act as study guarantor.

\section{DETAILS OF ETHICS APPROVAL}

The UKOSS general methodology (04/MRE02/45) and this study (06/MRE02/77) were approved by the London Research Ethics Committee. 


\section{FUNDING}

This paper reports on an independent study which was funded by the Policy Research Programme in the Department of Health. The views expressed are not necessarily those of the Department. MK is funded by the National Coordinating Centre for Research Capacity Development of the National Institute for Health Research. The funding sources played no part in the design, data collection, analysis, and interpretation in the writing of the paper or the decision to submit the paper for publication.

The first author is a Chief Investigator on the Australasian Maternity Outcomes Surveillance System (AMOSS), a study similar to UKOSS. This work was undertaken when she was a Visiting Academic at the National Perinatal Epidemiology Unit as part of the AMOSS Project. 


\section{References}

1. World Health Organisation. Global Strategy on Diet, Physical Activity and Health: Obesity and Overweight. [cited 20/01/2010]; Available from: http://www.who.int/dietphysicalactivity/publications/facts/obesity/en/

2. Poobalan AS, Aucott LS, Gurung T, Smith WC, Bhattacharya S. Obesity as an independent risk factor for elective and emergency caesarean delivery in nulliparous women--systematic review and meta-analysis of cohort studies. Obes Rev 2009 Jan;10(1):28-35.

3. Zhang J, Bricker L, Wray S, Quenby S. Poor uterine contractility in obese women. BJOG 2007 Mar;114(3):343-8.

4. Rocke DA, Murray WB, Rout CC, Gouws E. Relative risk analysis of factors associated with difficult intubation in obstetric anesthesia. Anesthesiology 1992 Jul;77(1):67-73.

5. Whitty RJ, Maxwell CV, Carvalho JC. Complications of neuraxial anesthesia in an extreme morbidly obese patient for Cesarean section. Int J Obstet Anesth 2007 Apr;16(2):139-44.

6. Hodgkinson R, Husain FJ. Caesarean section associated with gross obesity. Br J Anaesth 1980 Sep;52(9):919-23.

7. Loverro G, Greco P, Vimercati A, Nicolardi V, Varcaccio-Garofalo G, Selvaggi L. Maternal complications associated with cesarean section. J Perinat Med 2001;29(4):322-6.

8. Perlow JH, Morgan MA. Massive maternal obesity and perioperative cesarean morbidity. Am J Obstet Gynecol 1994 Feb;170(2):560-5.

9. Modder J, Fitzsimon K. CMACE/RCOG Joint Guideline: Management of Women with Obesity in Pregnancy. London: CMACE/RCOG; 2010.

10. Knight $M$, Kurinczuk JJ, Spark $P$, Brocklehurst $P$. Extreme obesity in pregnancy in the United kingdom. Obstet Gynecol 2010 May;115(5):989-97.

11. Knight M, Kurinczuk JJ, Tuffnell D, Brocklehurst P. The UK Obstetric Surveillance System for rare disorders of pregnancy. BJOG 20052005 Mar;112(3):263-5.

12. Chauhan SP, Magann EF, Carroll CS, Barrilleaux PS, Scardo JA, Martin JN, Jr. Mode of delivery for the morbidly obese with prior cesarean delivery: vaginal versus repeat cesarean section. Am J Obstet Gynecol 2001 Aug;185(2):349-54.

13. Hibbard JU, Gilbert S, Landon MB, Hauth JC, Leveno KJ, Spong CY, et al. Trial of labor or repeat cesarean delivery in women with morbid obesity and previous cesarean delivery. Obstet Gynecol 2006 Jul;108(1):125-33.

14. Varma R, Gupta JK, Smith GCS. Birth after previous caesarean birth. London: RCOG; 2007.

15. Al Hadi M, Geary M, Byrne P, McKenna P. Shoulder dystocia: risk factors and maternal and perinatal outcome. J Obstet Gynaecol 2001 Jul;21(4):352-4.

16. Gherman RB, Ouzounian JG, Goodwin TM. Obstetric maneuvers for shoulder dystocia and associated fetal morbidity. Am J Obstet Gynecol 1998 Jun;178(6):1126-30.

17. Royal College Of Obstetricians and Gynaecologists. Shoulder Dystocia. Green-top guideline no. 42. London: Royal College Of Obstetricians and Gynaecologists; 2005.

18. Nesbitt TS, Gilbert WM, Herrchen B. Shoulder dystocia and associated risk factors with macrosomic infants born in California. Am J Obstet Gynecol 1998 Aug;179(2):476-80.

19. McDonnell NJ, Paech MJ, Clavisi OM, Scott KL. Difficult and failed intubation in obstetric anaesthesia: an observational study of airway management and complications associated with general anaesthesia for caesarean section. Int J Obstet Anesth 2008 Oct;17(4):292-7.

20. The UK Obstetric Surveillance System. 2008 [cited February 2008]; Available from: http://www.npeu.ox.ac.uk/ukoss

21. Knight M. Eclampsia in the United Kingdom 2005. BJOG 20072007 Sep;114(9):1072-8. 
22. Knight $M$, Kurinczuk JJ, Spark P, Brocklehurst P. Cesarean delivery and peripartum hysterectomy. Obstet Gynecol 20082008 Jan;111(1):97-105.

23. Knight $M$, Nelson-Piercy $C$, Kurinczuk JJ, Spark P, Brocklehurst P. A prospective national study of acute fatty liver of pregnancy in the UK. Gut $2008 \mathrm{Jul} ; 57(7): 951-6$. 
Table 1: Demographic characteristics, pregnancy events and complications by planned mode of birth

\begin{tabular}{|c|c|c|c|}
\hline & $\begin{array}{c}\text { Planned vaginal } \\
\text { delivery } \\
\mathrm{N}=417(\% *)\end{array}$ & $\begin{array}{c}\text { Planned caesarean } \\
\text { delivery } \\
\mathrm{N}=174\left(\%^{*}\right)\end{array}$ & $P$ value \\
\hline \multicolumn{4}{|l|}{ Parity } \\
\hline - Primiparous & $162(38.9)$ & $40(23.1)$ & \\
\hline - Multiparous & $255(61.1)$ & $54(76.9)$ & $<0.001$ \\
\hline \multicolumn{4}{|l|}{ Age } \\
\hline - $\quad<35$ years & $322(77.2)$ & $112(64.4)$ & \\
\hline - $\quad \geq 35$ years & $95(22.8)$ & $62(35.6)$ & 0.001 \\
\hline \multicolumn{4}{|l|}{ Ethnicity } \\
\hline - White & $366(88.6)$ & $147(87.0)$ & \\
\hline $\begin{array}{l}\text { - Black and other minority } \\
\text { groups }\end{array}$ & $47(11.4)$ & $22(13.0)$ & 0.579 \\
\hline \multicolumn{4}{|l|}{ Socioeconomic group } \\
\hline - Managerial/professional & $288(83.2)$ & $112(80.0)$ & \\
\hline - Other & $58(16.8)$ & $28(20.0)$ & 0.397 \\
\hline \multicolumn{4}{|l|}{ BMI } \\
\hline - $\quad 50-54$ & $278(66.7)$ & $108(62.1)$ & \\
\hline - $\quad 55-59$ & $90(21.6)$ & $40(23.0)$ & \\
\hline - $60-64$ & $35(8.4)$ & $15(8.6)$ & \\
\hline - $\quad \geq 65$ & $14(3.4)$ & $11(6.3)$ & 0.423 \\
\hline \multicolumn{4}{|l|}{ Previous medical conditions } \\
\hline - Hypertension & $19(4.6)$ & $19(11.1)$ & 0.004 \\
\hline - Asthma & $51(12.2)$ & $21(12.1)$ & 0.956 \\
\hline - Endocrine disorders & $13(3.1)$ & $9(5.1)$ & 0.229 \\
\hline - Diabetes & $17(4.1)$ & $12(6.9)$ & 0.148 \\
\hline - Mental health problems & $41(9.8)$ & 19 (10.9) & 0.690 \\
\hline - Polycystic ovarian syndrome & $22(5.3)$ & $4(2.3)$ & 0.108 \\
\hline \multicolumn{4}{|l|}{ Previous obstetric conditions } \\
\hline - Gestational diabetes (GDM) & $14(3.4)$ & $8(4.6)$ & 0.468 \\
\hline $\begin{array}{l}\text { Pre-eclampsia or Pregnancy } \\
\text { induced hypertension } \\
\text { (PE/PIH) }\end{array}$ & $39(9.4)$ & $26(14.9)$ & 0.048 \\
\hline $\begin{array}{l}\text { Composite antenatal medical risk } \\
\text { factor** }\end{array}$ & $139(33.3)$ & $86(49.4)$ & $<0.001$ \\
\hline \multicolumn{4}{|l|}{ Current obstetric conditions } \\
\hline - Previous CS & $26(6.2)$ & $74(42.5)$ & $<0.001$ \\
\hline - Multiple pregnancy & $6(1.4)$ & $11(6.3)$ & 0.001 \\
\hline - $\mathrm{PE} / \mathrm{PIH}$ & $88(21.1)$ & $47(27.0)$ & 0.119 \\
\hline - GDM & $37(8.9)$ & $32(18.4)$ & 0.001 \\
\hline - Thrombotic event & $3(0.7)$ & $0(0)$ & 0.265 \\
\hline
\end{tabular}

*Percentages of those with data

**Composite antenatal medical risk factor: one or more of the following: pre-existing diabetes, asthma, hypertension or endocrine disorder; and/or current gestational diabetes, pre-eclampsia or a thromboembolic event in this pregnancy 
Table 2: Factors associated with actual delivery by caesarean in extremely obese women, irrespective of planned mode of delivery

\begin{tabular}{|c|c|c|c|c|c|c|}
\hline & \multicolumn{2}{|c|}{ Vaginal delivery } & \multicolumn{2}{|l|}{ CS } & \multirow{2}{*}{$\begin{array}{l}\text { Unadjusted } \\
\text { OR }(95 \% \mathrm{Cl})\end{array}$} & \multirow{2}{*}{$\begin{array}{l}\text { Adjusted* } \\
\text { OR }(95 \% \mathrm{Cl})\end{array}$} \\
\hline & $\mathrm{N}=\mathbf{2 9 0}$ & $\%$ & $N=301$ & $\%$ & & \\
\hline \multicolumn{7}{|l|}{ Age } \\
\hline$<25$ years & 59 & 20.3 & 38 & 12.6 & 1.0 & 1.0 \\
\hline $25-34$ years & 170 & 58.7 & 167 & 55.5 & $1.52(0.96-2.41)$ & $1.20(0.68-2.13)$ \\
\hline$\geq 35$ years & 61 & 21.0 & 96 & 31.9 & $2.44(1.45-4.10)$ & $1.50(0.78-2.86)$ \\
\hline \multicolumn{7}{|l|}{ Ethnic group } \\
\hline White & 253 & 87.9 & 260 & 88.4 & 1.0 & 1.0 \\
\hline All other groups & 35 & 12.1 & 34 & 11.6 & $0.95(0.57-1.56)$ & $0.86(0.46-1.60)$ \\
\hline \multicolumn{7}{|l|}{ SES status } \\
\hline Non-managerial & 199 & 85.0 & 201 & 79.8 & 1.0 & 1.0 \\
\hline Managerial & 35 & 15.0 & 51 & 20.2 & $1.44(0.90-2.31)$ & $1.65(0.99-2.76)$ \\
\hline \multicolumn{7}{|l|}{ Previous CS } \\
\hline No & 281 & 96.9 & 210 & 69.8 & 1.0 & 1.0 \\
\hline Yes & 9 & 3.1 & 91 & 30.2 & $13.5(6.67-27.46)$ & $16.7(7.06-39.7)$ \\
\hline \multicolumn{7}{|c|}{ Past or current diabetes (including GDM in this pregnancy) } \\
\hline No & 258 & 89.0 & 240 & 79. & 1.0 & 1.0 \\
\hline Yes & 32 & 11.0 & 61 & 20.3 & $2.05(1.29-3.25)$ & $2.08(1.20-3.59)$ \\
\hline \multicolumn{7}{|l|}{ BMI } \\
\hline$<60$ & 256 & 88.3 & 260 & 86.4 & 1.0 & 1.0 \\
\hline$>60$ & 34 & 11.7 & 41 & 13.6 & $1.19(0.73-1.93)$ & $1.14(0.63-2.06)$ \\
\hline \multicolumn{7}{|l|}{ Multiple pregnancy } \\
\hline No & 286 & 98.6 & 288 & 95.7 & 1.0 & 1.0 \\
\hline Yes & 4 & 1.4 & 13 & 4.3 & $3.23(1.04-10.02)$ & $3.42(0.85-13.79)$ \\
\hline
\end{tabular}


Table 3: Anaesthetic, postnatal and neonatal complications by planned mode of birth

\begin{tabular}{|c|c|c|c|c|}
\hline & $\begin{array}{c}\text { Vaginal } \\
\mathrm{N}=417 \text { (\%) }\end{array}$ & $\begin{array}{l}\text { Caesarean } \\
\mathrm{N}=174(\%)\end{array}$ & $\begin{array}{c}\text { Unadjusted } \\
\text { OR } \\
(95 \% \mathrm{Cl})\end{array}$ & $\begin{array}{l}\text { Adjusted OR } \\
(95 \% \mathrm{Cl})^{* *}\end{array}$ \\
\hline \multicolumn{5}{|l|}{ Caesarean delivery } \\
\hline & $127(30.5)$ & $174(100)$ & NA & NA \\
\hline \multicolumn{5}{|l|}{ Anaesthetic } \\
\hline $\begin{array}{l}\text { - Failure or problems with } \\
\text { regional anaesthesia }\end{array}$ & $35(8.4)$ & $18(10.3)$ & $\begin{array}{l}0.79(0.44- \\
1.44)\end{array}$ & $0.72(0.37-1.39)$ \\
\hline $\begin{array}{l}\text { - General anaesthetic for } \\
\text { delivery }\end{array}$ & $22(5.3)$ & $15(8.6)$ & $\begin{array}{l}0.59(0.30- \\
1.17)\end{array}$ & $0.55(0.26-1.16)$ \\
\hline \multicolumn{5}{|l|}{ Maternal postnatal } \\
\hline $\begin{array}{l}\text { - Post operative wound } \\
\text { infection or other wound } \\
\text { complication }{ }^{\dagger}\end{array}$ & $33(26.2)$ & $38(22.4)$ & $\begin{array}{l}1.23(0.72- \\
2.11)\end{array}$ & $1.20(0.68-2.13)$ \\
\hline - ICU admission & $9(2.2)$ & $6(3.5)$ & $\begin{array}{l}0.61(0.22- \\
1.75)\end{array}$ & $0.62(0.19-2.07)$ \\
\hline - Major maternal morbidity* & $18(4.3)$ & $11(6.3)$ & $\begin{array}{c}0.67(0.31- \\
1.45)\end{array}$ & $0.53(0.23-1.24)$ \\
\hline \multicolumn{5}{|l|}{ Neonatal } \\
\hline - Birthweight 4500 g or greater & $35(8.4)$ & $22(12.7)$ & $\begin{array}{l}0.63(0.36- \\
1.11)\end{array}$ & $0.60(0.32-1.12)$ \\
\hline - $\quad$ Shoulder dystocia & $13(3.1)$ & $0(0)$ & $\infty(1.44-\infty)$ & NC \\
\hline $\begin{array}{l}\text { - Neonatal Intensive care unit } \\
\text { admission }\end{array}$ & $34(8.3)$ & $27(15.5)$ & $\begin{array}{c}0.49(0.29- \\
0.84)\end{array}$ & $0.67(0.34-1.30)$ \\
\hline - Neonatal death & $2(0.5)$ & $1(0.6)$ & $0.85(0.08-9.4)$ & $1.08(0.09-13.2)$ \\
\hline \multicolumn{5}{|c|}{$\begin{array}{l}\text { *Composite score including one or more of the following: intraoperative or postpartum haemorrhage, thromboembolic event, } \\
\text { septicaemia, septic shock and/or admission to an intensive care unit. } \\
\text { **Adjusted for the presence of one or more of the following: pre-existing diabetes, asthma, hypertension or endocrine disorder; } \\
\text { and/or gestational diabetes, pre-eclampsia or a thromboembolic event in this pregnancy, previous delivery by caesarean } \\
\text { section. Neonatal outcomes additionally adjusted for preterm delivery (gestation less than } 37 \text { completed weeks at birth) } \\
\text { NA Not applicable, NC Not calculable due to zero cells }\end{array}$} \\
\hline
\end{tabular}


Table 4: Sensitivity analysis to examine anaesthetic, postnatal and neonatal complications by planned mode of birth excluding women with known antenatal complications***

$\begin{array}{cccc}\text { Vaginal } & \text { Abdominal } & \text { Unadjusted } & \begin{array}{c}\text { Adjusted OR } \\ \mathrm{N}=288(\%)\end{array} \\ & \mathrm{N}=88(\%) & \mathrm{OR} & (95 \% \mathrm{Cl})^{* *} \\ & & (95 \% \mathrm{Cl}) & \end{array}$

\begin{tabular}{lcccc}
\hline Caesarean delivery & $76(27.3)$ & $88(100)$ & NA & NA \\
$\begin{array}{l}\text { Anaesthetic } \\
\text { - } \quad \begin{array}{l}\text { Failure or problems with } \\
\quad \text { regional anaesthesia }\end{array}\end{array}$ & $19(6.8)$ & $8(9.1)$ & $\begin{array}{c}0.73(0.31- \\
1.74)\end{array}$ & $0.67(0.25-1.78)$ \\
- General anaesthetic for & $13(4.7)$ & $6(6.8)$ & $\begin{array}{c}0.67(0.25- \\
1.82)\end{array}$ & $0.62(0.20-1.92)$ \\
$\quad \begin{array}{l}\text { delivery } \\
\text { Maternal postnatal } \\
\text { - Post operative wound }\end{array}$ & $19(25.0)$ & $15(17.7)$ & $\begin{array}{c}1.56(0.73- \\
3.33)\end{array}$ & $1.43(0.64-3.22)$ \\
$\quad \begin{array}{l}\text { infection or other wound } \\
\text { complicationt }\end{array}$ & & & $0.51(0.12-$ & $0.29(0.07-1.25)$ \\
- ICU admission & $5(1.8)$ & $3(3.5)$ & $2.19)$ & $0.34(0.11-1.04)$ \\
- Major maternal morbidity* & $10(3.6)$ & $5(5.7)$ & $\begin{array}{c}0.62(0.21- \\
1.86)\end{array}$ &
\end{tabular}

Neonatal

- Birthweight $4500 \mathrm{~g}$ or greater

- Shoulder dystocia

- Neonatal Intensive care unit admission

- Neonatal death
$21(7.6) \quad 11(12.6)$

$0.45(0.26-$

$0.19(0.32-1.05)$

1.22)

$5(1.8)$

$0(0)$

$\infty(0.40-\infty)$

NC

$18(6.5)$

$7(8.0)$

$0.81(0.33-$

$0.79(0.28-2.25)$

2.00)

$2(0.5)$

$\infty(0.16-\infty)$

NC

tDenominator is women who had a caesarean delivery.

*Composite score including one or more of the following: intraoperative or postpartum haemorrhage, thromboembolic event, septicaemia, septic shock and/or admission to an intensive care unit.

${ }^{* *}$ Adjusted for previous delivery by caesarean section. Neonatal outcomes additionally adjusted for preterm delivery (gestation less than 37 completed weeks at birth)

***The presence of one or more of the following: pre-existing diabetes, asthma, hypertension or endocrine disorder; and/or gestational diabetes, pre-eclampsia or a thromboembolic event in this pregnancy.

NA Not applicable, NC Not calculable due to zero cells 
